E.L.U.A. 3, 1985-1986, págs. 209-235

\title{
ESPACIO Y ENUNCIACIÓN EN LA DINÁMICA TEXTUAL DE LA LENGUA ESPAÑOLA
}

\author{
JOSÉ LUIS CIFUENTES HONRUBIA \\ (Universidad de Murcia)
}

\section{Introducción}

En la investigación lingüística actual la necesidad de una teoría semiótica se ve cumplida desde el momento en que el texto pasa a convertirse en objeto lingüístico propio, con una funcionalidad lingüistica concreta, específica, dada por la intercomunicación funcional entre dos o más usuarios de la lengua, dialogismo en definitiva, siendo sus límites los que la intencionalidad comunicativa -o el estudio- imponga. Entenderemos texto como producción de sentido (Greimas, 1973), lo cual nos lleva a un estudio del planteamiento de la enunciación y, en definitva, a una identificación de la Lingüística del Texto con la Pragmática (Schmidt, 1977).

Tales investigaciones lingüisticas se incorporarian dentro de una semiótica general como interpretación del texto, a su vez incorporable dentro de una macrosemiótica, cuyo objeto de estudio no tiene por qué ser sólo textos lingüísticos (Greimas, 1980b). Debemos dejar bien claro que interpretamos semiótica no como ciencia del signo, sino como ciencia de la significación, es decir, el estudio del proceso comunicativo en su actividad, postulando significación como articulación de sentido. La semiótica se sirve de los signos, pero su interés es el proyecto comunicativo que lleva a esos signos. 


\section{La enunciación}

Un enunciado se convierte en acto lingüístico al recorrer la instancia de la enunciación. En un enunciado distinguimos lo que se dice y el hecho de decirlo, pero el sentido de un enunciado no puede considerarse independiente del hecho de su enunciación.

Desde una perspectiva «representacionalista» (Ryle, 1957), un enunciado producto de la enunciación de una expresión lingüistica en un contexto es un hecho, pero este hecho no es considerado como tal, ya que remite al estado de cosas que significa o representa, de modo que la enunciación está como puesta entre paréntesis en favor de lo significado por su intervención. Oponiéndonos (Récanati, 1981) a la concepción identificadora del sentido del enunciado con lo que éste representa, defendemos que el sentido del enunciado está constituido -además de su contenido representativo- por las indicaciones que reflexivamente atañen al hecho de su enunciación. La enunciación no debe ser puesta entre paréntesis para que el enunciado signifique puesto que se refleja en el sentido del enunciado, distinguiendo de su contenido representativo.

\subsection{Reflexividad y enunciación}

Todos los enunciados —n tanto 'objeto' de una enunciación-son actos de discurso, y por ello todos son realizativos; es decir, todos los enunciados son contextos opacos, porque las palabras no son utilizadas de un modo puramente transparente y no desaparecen completamente delante de lo que representan.

Cada enunciado tiene una dimensión "constatativa» y una dimensión "realizativa», esta es la tesis fundamental que podemos denominar segunda teoría austiniana (Austin, 1971). Austin, al abandonar la oposición realizativo vs. constatativo distingue en todo enunciado un aspecto locucionario y un aspecto ilocucionario, estando ambos generalmente ligados. El aspecto locucionario es lo que se dice, es el «contenido" del enunciado, el "pensamiento», o la "proposición» que él expresa. El aspecto ilocucionario es el enunciado en tanto acto, es el hecho de decir lo que se dice, en la medida en que decir es actuar, es realizar un acto ilocucionario, tal como promesa, orden, pregunta, etc. (También se puede distinguir un problemático aspecto perlocucionario, que remite al efecto producido por la ilocución; así, determinada pregunta del hablante puede servir para confundir a un adversario, o para 
permitirle integrarse a una discusión, etc.). Sin embargo no podemos separar estos aspectos más que por abstracción.

En nuestra conceptualización de los actos de discurso podemos ligar los aspectos locutivo e ilocutivo-perlocutivo de Austin, al esquema dialéctico presentado por Wittgenstein (1973) entre el decir y el mostrar: hay una forma de decir sin decir: mostrando. El lenguaje no sólo representa, sino que también muestra, y muestra precisamente lo que no puede representar: la reflexividad desterrada del dominio de la representación es lícita en la mostración; el representante se muestra, exhibe sus propiedades formales al mismo tiempo que representa lo representado. El sentido de una expresión lingüística está constituido por lo que significa y por lo que muestra.

\subsection{Decir y mostrar}

Se hace necesario señalar el carácter doble de los enunciados realizativos, que descansan a la vez sobre ellos mismos y sobre la realidad de la que hablan, que mezclan, en su reflexión, los niveles del lenguaje, el decir y el mostrar.

Podemos distinguir entre el texto y el margen (Récanati, 1981); el texto es texto de lo que se enuncia y en el margen encontramos las indicaciones que le conciernen. Un elemento lingüístico no significa sólo por su contenido sino también por su forma: al lado de lo que se dice está aquello que, lateral o marginalmente, muestra. La indicación reflexiva que un enunciado ofrece acerca de su estatus formal es marginal, y permanece aún cuando sea explicitada. Así, el modo verbal, la entonación y el contexto de la enunciación ofrecen una indicación concerniente al estatus del enunciado, pero ésta también puede ser ofrecida explícitamente por el verbo realizativo.

El acontecimiento espacio-tempo-actorialmente determinado es el decir o la enunciación, pero la enunciación no es un acontecimiento como los otros, pues una determinación la singulariza: está dotada de significación. Para establecer la relación entre el hecho de decir y lo que se dice, se ha ofrecido la distinción entre type vs. token=tipo vs. ejemplar.

Al significado del tipo se opone el significado del ejemplar y éste está constituido por el suplemento que aporta al sentido de un enunciado, es decir, la mostración de sí mismo que efectúa reflexivamente gracias a un cierto número de indicadores. Debido a estos indicadores reflexivos (entonación, mímica, situación) el enunciado significa en principio que significa, teniendo también que significar lo que significa. 


\subsubsection{Las expresiones ejemplar-reflexivas}

Es imposible determinar (Récanati, 1981) el contenido proposicional de un enunciado si no se considera, además de lo que el «tipo» significa, lo que el contexto de enunciación muestra; y ciertas expresiones que figuran en la oración, al reflejar el hecho de la enunciación tienen precisamente como función incitar a tomar en consideración dicho contexto. Estas expresiones, denominadas ejemplar-reflexivas, reflejan la enunciación del ejemplar tanto como los indicadores modales, que añaden al contenido proposicional del enunciado un suplemento entre paréntesis relativo al valor de enunciación, pero la reflexión del ejemplar que ellos efectúan es constitutiva del contenido proposicional del enunciado y, por lo tanto, no se limita a añadirle un incremento de sentido. F. Récanati (1981: 140) caracteriza las expresiones ejemplarreflexivas de la siguiente forma:

«La opacidad de las expresiones ejemplar-reflexivas es una condición sine qua non de su transparencia: no podemos acceder a lo que ellas representan sin tomar en consideración lo que son, y ellas mismas nos muestran lo que son al reflejar su propia factualidad de ejemplares. Estas expresiones son embragues pues apuntan desde el sentido que tienen en tanto signos, hacia lo que son en tanto cosas, hacia el hecho que ellas mismas constituyen. Para representar las cosas se presentan ellas mismas como cosas, y al exhibir la pertenencia del discurso al mundo le permiten representarlo».

Todo enunciado, en tanto ejemplar resultante de la enunciación de una expresión lingüistica en un contexto, muestra -con o sin ambigüedad- qué acto de discurso constituye; todo enunciado, en consecuencia, refleja lo que es en tanto ejemplar y puede denominarse ejemplar-reflexivo. Si las expresiones ejemplar-reflexivas son sistemáticamente ambiguas también lo son las oraciones que contienen tales enunciados: la reflexividad de ejemplar se transmite de las palabras a los enunciados.

Una expresión ejemplar-reflexiva, en tanto tipo, no tiene un sentido determinado, sino una significación que se transforma en un sentido determinado cuando la enunciación tiene lugar en el contexto de un ejemplar particular de esta expresión; entonces, lo que significa el tipo es completado por lo que el ejemplar muestra, que refleja el hecho de su propia enunciación e impele a tomar en consideración el contexto 
del que proviene. Por tanto es necesario considerar a estos enunciados como hechos, como acontecimientos, para acceder a su sentido.

Según Bar-Hillel (1973:109) «ninguna expresión lingüística es completamente independiente del contexto pragmático», además, habrá otras oraciones en las que este "contexto pragmático", será el fenómeno fundamental para su ser comunicativo: las expresiones ejemplarreflexivas.

La comunicación efectiva por medio de expresiones indicadoras (ejemplar-reflexivas) exige que el destinatario conozca el contexto pragmático de la producción de los ejemplares. Un gran problema (BarHillel, 1973) consiste en el hecho de que el contexto pragmático, tal como es conocido por quien produce la expresión y supuesto como tácitamente entendido en cualquier acto de comunicación, no requiere ser entendido de aquella misma manera por un destinatario y puede serlo de maneras diversas por destinatarios distintos. La confusión será un precio no muy elevado que debe pagarse por la brevedad, inmediatez y otras ventajas de la comunicación indicadora (Antinucci, 1974). El peligro principal de la comunicación indicadora (Bar-Hillel, 1973) no consiste, sin embargo, en este hecho obvio, sino en que la dependencia respecto del contexto pragmático puede a veces ser olvidada, de modo que el destinatario estará inclinado a suministrar inconscientemente algún contexto al ejemplar de expresión recibido, pero no el contexto que quien lo produjo tuvo en mira, y de esa manera dicho destinatario tendrá la impresión de haber recibido un enunciado-ejemplar que no presenta problemas especiales de referencia.

El carácter realizativo generalizado por Austin (1971) nos lleva (Récanati, 1981) a universalizar la dependencia contextual, pues para comprender un enunciado, sea cual sea, es preciso determinar qué acto de discurso instaura su enunciación, lo que implica considerarlo como un hecho que tiene lugar en un contexto (ya que un acto de discurso es un hecho).

Es cierto que la dependencia del enunciado respecto de lo que muestra el contexto de la enunciación se extiende al menos tan lejos como se extienda la reflexividad de ejemplar. Ahora bien, ésta se extiende bastante lejos en la medida en que, por ejemplo, los tiempos verbales así como los pronombres personales o los locativos espaciales, son expresiones ejemplar-reflexivas, que, como todas las expresiones ejemplar-reflexivas, reflejan como ejemplar el enunciado del que forman parte.

Es preciso añadir a lo que significa el enunciado lo que el hecho de su enunciación muestra. La significación de los enunciados incluye, por tanto, una referencia virtual a los ejemplares que deben encua- 
drarlos, y cuando se los enuncia esta referencia se actualiza, de modo que en el sentido' de los enunciados se refleja el hecho de su enunciación. Siempre es el hecho de su enunciación el que sirve de punto de referencia, por ejemplo, a las indicaciones espaciales. La reflexividad de ejemplar es el único medio del que disponemos para hacer referencia a los objetos singulares, es decir, a los objetos situados en un marco espacio-temporal. La singularidad del ejemplar en vías de enunciación es el punto de referencia universal a partir del cual se ordena el sistema de identificaciones individualizantes.

Según Austin (1971) todo enunciado refleja, explícita o implícitamente, su ser como ejemplar, como evento singular, como acto de discurso inserto en un contexto: todo enunciado se muestra reflexivamente y muestra cómo debe ser captado indicando particularmente la fuerza ilocucionaria de la que está dotado.

La reflexividad es una característica esencial de la comunicación intencional. Para que haya comunicación en un sentido fuerte es preciso que se comunique intencionalmente no sólo cierto contenido, sino además el hecho de que ese contenido se comunica intencionalmente. La comunicación intencional debe establecerse como tal al mismo tiempo que se realiza: el hecho de la comunicación se refleja y forma parte de aquello que se comunica. Al lado de lo que implica lo que se dice está aquello que el hecho de decirlo implica; al lado de las implicaciones lógicas están las implicaciones pragmáticas del decir.

\section{La situación de enunciación}

Hemos hablado en el punto anterior repetidas veces acerca del contexto pragmático o contexto de enunciación, $y$, a pesar de la vaguedad con que ha sido tratado quizás podría desprenderse su identificación con el encuadre espacio-temporal del enunciado, teniendo en cuenta, evidentemente, los distintos intercambios yo-tú de la comunicación. D. Wunderlich (1972) ha tratado de llevar a cabo un intento de sistematización de este fenómeno, sin embargo excluye de la consideración del contexto pragmático dos importantes apartados: Ios presupuestos conceptuales que son consecuencia de experiencias particulares y las relaciones cognoscitivas o comunicativas anteriores a la situación de enunciación.

El contexto pragmático, abstraído de esas dos premisas, será de-

1 Para una aclaración del término usentido" véase Strawson 1970, y la tercera propuesta que sobre tal vocablo realiza. 
nominado por Wunderlich situación de enunciación, la cual siempre ha sido muy problemática (Antinucci, 1974, 1976; Cinque, 1976), sin embargo el estudio de Wunderlich merece ser asumido en su totalidad. En su ya clásico trabajo (1972) expone que cada "situación de enunciación" comporta dos elementos principales: 1) lo que enuncia un locutor, y 2) una interrelación (o, mejor, una interacción), establecida por esta enunciación entre emisor y receptor. La interacción entre emisor y receptor no debe reducirse a alguna forma de contenido cognoscitivo del enunciado, sino que representa el efecto irreductible propio de la comunicación lingüística. Según Wunderlich la descripción completa de una situación de enunciación comportaría un número de 9 elementos, y su esquema sería el siguiente (Wunderlich, 1972:49):

Sit $=<$ Loc, Aud, d, I+p, Fon, Cont, Presup, Intec, Rel $>$ Sit $=$ situación de enunciación.

Loc $=$ locutor (emisor).

Aud $=$ auditor (interlocutor).

$\mathrm{d}=$ momento de la enunciación ${ }^{2}$.

$\mathrm{I}+\mathrm{p}=$ lugar y espacio perceptivo del emisor ${ }^{3}$.

Fon $=$ particularidades fono-sintácticas del enunciado.

Con $=$ contenido cognoscitivo del enunciado.

Presup = presuposición del locutor, necesariamente ligada a un enunciado; estas presuposiciones comportan al menos 5 subcomponentes:

Presup-LoC = sus conocimientos y capacidades.

Presup-Aud = lo que supone que son los conocimientos y capacidades del auditor.

Presup-Aud-P = lo que supone que es el espacio perceptivo del auditor.

Presup-Soc = la relación social entre locutor e interlocutor.

Presup-Text = lo que ha comprendido de enunciados anteriores. Inten = la intención del locutor ligada a este enunciado.

Rel = la interrelación entre locutor e interlocutor establecida por este enunciado.

2 Como el mismo Wunderlich comenta, es preciso distinguir dos tiempos en el momento de la enunciación: momento de la producción y momento de la recepción. Es evidente que la pertinencia de esta división tendrá lugar cuando exista un desfase temporal entre ambos momentos (Huddleston, 1969) y su sucesividad o linealidad temporal se vea interrumpida.

3 También es útil precisar si emisor y receptor se encuentran en un mismo lugar; puede haber una distancia espacial entre ambos (ej.: comunicación telefónica) que es imprescindible considerar para la exacta comprensión de ciertos deicticos espaciales, por ejempio. 


\subsection{Expresiones ejemplar-reflexivas}

Wunderlich, en este mismo trabajo de 1972, enumera una serie de fenómenos que remiten obligatoriamente a la situación de enunciación. Este tipo de fenómemos coincidirian con las anteriormente llamadas expresiones ejemplar-reflexivas, $y$, aunque lejos en sus pretensiones de ser un listado exhaustivo de los componentes de este tipo de expresiones, no cabe duda de que su exposición puede ser muy aleccionadora:

A) Enunciados con deixis implícita: se trata de una serie de verbos locales con implicaciones deícticas (Fillmore, 1966, 1971b, 1972; Tanz, 1980).

B) Relaciones entre los diálogos: la descripción gramatical debe mostrar que "yo» y «tú» (con sus composiciones espaciales o temporales) pueden designar el mismo referente cuando son enunciados por locutores diferentes (Bühler, 1979; Heger, 1974; Vera, 1979; Tanz, 1980).

C) El «honorativo»: hay en algunas lenguas unas formas personales y posesivas de primera y segunda persona, que no sólo designan el locutor e interlocutor, sino además la relación social existente entre ellos.

D) Condiciones de coherencia de los textos: en este punto Wunderlich se refiere esencialmente al contenido anafórico o catafórico de determinados artículos y pronombres (Weinrich, 1982; Dressler, 1974) y su conocimiento o identificación por el locutor. (Un mayor desarrollo de este aspecto podemos encontrarlo en Greimas, 1971; Schmidt, 1977; Van Dijk, 1980; Petöfi-García Berrio, 1979; Albaladejo-García Berrio, 1983; y en especial Ramón Trives, 1979).

E) Saber o presuposición. (A este respecto son muy interesantes las aportaciones de Schmidt, 1977; y Ducrot, 1981).

F) Ciertas frases, que comportan formas personales o reflexivas, pueden ser dominadas por una frase (desaparecida en superficie) del tipo «Yo te digo que...» (Austin, 1971; Searle, 1980; Récanati, 1981).

G) Vocativo, imperativo, interrogación. En definitiva a lo que se refiere es a la modalidad; este tema podemos encontrarlo más actualizado en Darrault, 1976; Greimas-Courtés, 1982. La modalidad, estando vinculada a las expresiones ejemplar-reflexivas, se separa del resto debido a sus especiales características.

H) Expresiones deícticas. Considero que es el más importante de los fenómenos aquí expuestos (emparejado con la modalidad), su valor depende siempre de quién, dónde y cuándo son expresados. Si lo he expuesto alterando el orden de Wunderlich es porque sobre este punto articularemos ciertas precisiones y añadiduras. Así, más adelante, tra- 
taremos de demostrar por qué los deícticos remiten a la enunciación, y en especial los locativos deícticos espaciales, pero junto a ellos incorporaremos otro tipo de locativos espaciales no deícticos que podríamos denominar intrínsecos o inherentes.

\section{Dialogismo}

Las expresiones ejemplar-reflexivas, principal elemento de la enunciación, se verían acogidas por lo que Weinrich $(1979,1982)$ denomina lenguaje imputable: expresiones que son al mismo tiempo acciones y que, por serlo, obligan al hablante de la misma manera que lo obligan las acciones que el enunciador puede ejecutar de manera no verbal.

El lenguaje imputable formaria parte de la teoria lingüistica llamada por Weinrich «de la instrucción» donde el concepto de instrucción sirve para dinamizar el modelo de la comunicación: el signo lingüístico es un segmento textual por medio del cual el emisor induce al receptor a comportarse de una cierta manera, el signo lingüístico es un acto instructivo en una situación comunicativa. En la totalidad de instrucciones que el código de la lengua pone a disposición de los usuarios es a las expresiones ejemplar-reflexivas a quienes les corresponde la tarea metacomunicativa de informar al receptor sobre la manera en la cual debe entenderse la estructuración del texto para descodificarlo correctamente y aprehender el sentido que el emisor ha querido otorgarle. Tal esquema teórico presupone una concepción del lenguaje que no es monológica, sino dialógica, siendo este uno de los pilares fundamentales de la enunciación.

\section{Enunciación y teoría semiótica}

Podemos definir la enunciación como una instancia lingüística, lógicamente presupuesta por la existencia misma del enunciado y que conlleva una serie de rasgos o marcas; estas marcas serán las expresiones ejemplar-reflexivas. Por lo tanto al considerar el enunciado como el resultado alcanzado por la enunciación (Greimas-Courtés, 1982), ésta funcionará como la instancia de mediación que asegura la aparición en enunciado-discurso de las virtualidades de la lengua, con lo cual la enunciación se concebirá como un componente autónomo de la teoría del lenguaje, como una instancia que prepara el paso de la competencia a la realización -producción e interpretación-lingüística, de las estructuras semióticas virtuales o latentes -que deberá 
actualizar - a las estructuras realizadas bajo la forma de discurso. Consideraremos esas «estructuras virtuales o latentes» que la enunciación actualiza como el lugar en que residen las estructuras semionarrativas (Greimas-Courtés, 1982), estructuras que, una vez actualizadas operacionalmente, constituirán la competencia semiótica del sujeto de la enunciación.

Así pues, si la enunciación es el lugar donde se ejerce esta competencia semiótica, también será el lugar de interacción del sujeto de la enunciación; esquemáticamente podríamos considerarla como el egohic-nunc, y que, antes de que su actualización, está semióticamente vacío y semánticamente demasiado lleno, vendría a ser como una especie de depósito de sentido (Greimas-Courtés, 1982). Será la proyección -con los procedimientos de desembrague ${ }^{4}$-_ fuera de esta instancia, de los actantes del enunciado y de las coordenadas espaciotemporales, quien sitúe al sujeto de la enunciación por todo lo que no es él. Igualmente es el rechazo — gracias a los procedimientos de embrague ${ }^{5}$ - de las mismas categorías, destinado a cubrir el lugar imaginario de la enunciación, quien confiera al sujeto el estatuto ilusorio de constituirse como tal. (Estas categorías actoriales, espaciales y temporales cubrirían las expresiones ejemplar-reflexivas, en las que uno de sus elementos principales, la modalidad, podría ser separado metodológicamente dentro de otros apartados como el de la intencionalidad).

El conjunto de procedimientos capaces de instituir el discurso como un espacio y un tiempo, poblado por otros sujetos además del enunciador, constituirán la competencia discursiva. Si a esto agregamos el depósito de las figuras del mundo y de las configuraciones discursivas que permiten al sujeto de la enunciación ejercer su saber-hacer figurativo, la composición de la competencia discursiva se encontrará provisionalmente estructurada.

Pero el mecanismo de la enunciación, a pesar del provisional estado actual de las investigaciones, debe añadir otro elemento que lo pone en marcha y logra que la enunciación sea un acto. Este elemento es la

4 Podemos definir el desembrague (Greimas, 1983; Greimas-Courtés, 1982) como la operación que disjunta y proyecta fuera de la enunciación en el momento del acto del lenguaje y con miras a la manifestación-ciertos términos vinculados a su estructura de base, a fin de constituir así los elementos fundadores del enunciado-discurso. El acto de lenguaje constituirá pues el sujeto, espacio y tiempo de la enunciación, y, por otra parte, la representación actancial, temporal y espacial del enunciado.

5 El embrague se refiere al efecto de retorno a la enunciación exigido por la suspensión de la oposición entre ciertos términos de las categorias de persona y/o espacio y/o tiempo, así como por la denegación de la instancia del enunciado. Todo embrague presupone por tanto un desembrague que le es lógicamente anterior. (Greimas, 1983; Greimas-Courtés, 1982.) 
intencionalidad, que es interpretada como una «concepción del mundo", como una relación orientada transitiva, mediante la cual el sujeto se construye a sí mismo. Así pues, y según Greimas-Courtés (1982), «la enunciación es un enunciado cuya función predicado se denominaría intencionalidad y cuyo objeto seria el enunciado-discurso".

Por otra parte hay que considerar que la enunciación, en cuanto acto tiene como efecto producir la semiosis ${ }^{6}$, es decir, la serie continua de actos semióticos denominada manifestación.

El acto de significar tropezará entonces con las coerciones de la sustancia de la expresión, que obligan a intercalar procedimientos de textualización (ej.: unidimensional y lineal). Por supuesto que la enunciación, considerada desde el punto de vista del enunciatario, opera en sentido opuesto y procede en primer lugar a la abolición de toda linealidad.

Al distinguir por tanto dos niveles de profundidad y dos tipos de estructuras -semionarrativas y discursivas- rigiendo la organización del discurso, es necesario hablar acerca de los procedimientos de discursivización, los cuales, junto con la semántica discursiva, (cuyos componentes reconocidos, por el momento, son la tematización y figurativización) cubrirán la distancia que separa sintaxis y semántica narrativas de la representación sintáctico-semántica del texto, la cual, luego de la textualización, podrá servir de nivel profundo a las estructuras lingüísticas de superficie, en sentido chomskiano (GreimasCourtés, 1982).

6 P. A. Brandt ( Hacia una Semiótica Textual", VI-VII Curso de Lingüistica Textual, Universidad de Murcia, mayo, 1984) realiza ciertas precisiones al llamado recorrido generativo: antepone la semiosis a la narratividad, ya que -según Brandt-si no fuera así no podria dar cuenta de fenómenos tales como la espacialización. El esquema del recorrido generativo como modelo del mundo y de la comunicación quedaría por tanto del modo que sigue y donde la lexicalidad se distribuiría por todo el recorrído:

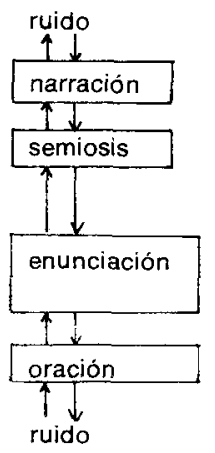

- física del significado

-descriptividad

- metafisica del significado (a la cual pertenecerian las categorias axiológicas profundas)

-localización

$\longrightarrow$ modalidades

-metafísica del significante

-física del significante 
Estos procedimientos de puesta en discurso, que componen la sintaxis discursiva, tienen en común el poder ser definidos como aplicación de las operaciones de desembrague y embrague, y, por tanto, dependen de la instancia de la enunciación. Tales procedimientos son tres: actorialización, temporalización y espacialización. Por tanto ya tenemos localizado y, creo, afirmado, la necesidad del estudio del subcomponente de espacialización que tratamos de caracterizar en el presente artículo.

\section{Espacialización y semiótica narrativa}

La espacialización está compuesta por dos procedimientos principales: 'localización espacial' y 'programación espacial'.

La 'localización espacial', al igual que la temporal, consiste en la inscripción de los programas narrativos dentro de las unidades espaciales —o temporales-; esto es realizado gracias a los procedimientos de desembrague. Sin embargo las posiciones así obtenidas son estáticas, es decir, representan enunciados de estado (Greimas-Courtés, 1982). En cuanto a los 'enunciados de hacer' deben ser interpretados como los pasos de un espacio a otro - de un intervalo temporal a otro-.

La localización espacial podrá definirse por tanto como «la construcción de un sistema de referencias que permite situar espacialmente los diferentes programas narrativos del discurso, unos en relación con otros» (Greimas-Courtés, 1982); y esto será posible gracias al desembrague espacial, el cual instala en el discurso enunciado un espacio del allá o espacio enuncivo, y un espacio del aquí o espacio enunciativo; los procedimientos de embrague harán que se mantengan relaciones estables entre ellos. Este allá y aquí discursivos son espacios cero, puntos de partida para intercalar las categorías de horizontalidad, verticalidad y prospectividad, (Greimas, 1971). Los espacios parciales se denominarán según la naturaleza de los actantes instalados y las «performances" que ellos cumplen?.

La localización espacial debe distinguirse de la 'espacialización cognoscitiva', que consiste en verter propiedades espaciales en las relaciones cognoscitivas entre los distintos actantes, lo cual nos introduce en la problemática de la proxémica, disciplina situada fuera de la semiótica discursiva (Greimas-Courtés, 1982).

7 Greimas, por ejemplo, articulará el espacio enuncivo en tópico, heterotópico, paratópico y utópico. 
En semiótica discursiva se entiende por programación espacial el procedimiento consistente, tras la localización espacial de los programas narrativos, en organizar el encadenamiento sintagmático de los espacios parciales. Esta programación espacial discursiva debe ser distinguida de la programación espacial efectuada en el campo de la semiótica del espacio -fuera de nuestras consideraciones - la cual pone en correlación los comportamientos programados de los sujetos con los espacios segmentados que ellos aprovechan (Greimas, 1980b; Boudon, 1981; Mountañola Thornberg, 1977).

En cuanto a los intentos de organización espacial de los discursos narrativos podemos mencionar dos proyectos, uno ya señalado: el de Greimas (nota 7), que articula el espacio enuncivo, y otro es el de Ulimer-Ehrich (1981), el cual, aunque parcial, por referirse a la descripción de habitantes, supone un importante paso investigador en el proyecto a seguir.

Una de las mayores utilidades de los criterios espaciales en su aplicación a la semiótica narrativa consiste en ser uno de los procedimientos fundamentales de segmentación (Greimas, 1980a; 1983; Greimas-Courtés, 1982). A la hora de la segmentación los criterios espaciotemporales presentan la ventaja de hallarse uniformemente presentes en todo discurso pragmático (sin embargo, no por ello debemos dar un carácter universal y jerárquico a la segmentación espacio-temporal).

\section{Localización espacial}

El componente de localización espacial va a venir dado primordialmente a través de dos grandes fenómenos: 'locativos deícticos' y 'locativos intrínsecos', y que, aunque separados, están fuertemente relacionados e imbricados, como tendremos oportunidad de mostrar.

Tomando como nuestras las palabras de Parisi-Castelfranchi, 1969, hemos de afirmar que la característica fundamental de la estructura semántica del mecanismo lingüístico usado para indicar el lugar, es el hecho de que en el lenguaje un lugar no puede venir identificado por sí mismo, sino que debe ser siempre identificado en relación a un objeto. La diferencia entre un locativo deíctico y uno intrínseco es que el deíctico suministra alguna información sobre el objeto (su relación con el hablante), mientras que el resto de la información la toma el receptor de la particular situación. El locativo intrínseco no posee ninguna información sobre el objeto, el receptor debe recabar de la particular situación toda la información necesaria para identificar el objeto.

El significado de un locativo es la relación que él especifica entre un 
lugar y el objeto, y esta relación sólo puede ser descrita tomando en consideración la estructura semántica del objeto (la cual está compuesta de dos componentes fundamentales: espacio y diferenciación; un objeto es cualquier cosa que introduce una diferenciación en el espacio, es decir, su característica principal sería la de ser discontinuo o discreto).

La deíxis es vista como una «figura de enunciación» (Benveniste, 1971; Antinucci, 1974; Ducrot-Todorov, 1974). Cuando el lenguaje es hablado ocurre en un lugar y tiempo, y con unas personas específicas. Los artificios que ligan la expresión con su contexto espacio-temporal actorial están recogidos bajo el término deíxis (Tanz, 1980). Así pues, y siguiendo en esta definición a J. Lyons por deíxis se entiende la

«localización e identificación de personas, objetos, eventos, procesos y actividades de las que se habla, o a las que se alude, en relación con el contexto espacio-temporal creado y sostenido por la enunciación y por la típica participación en ella de un solo hablante $y$, al menos un destinatario» (1980:574).

Es decir, los rasgos definitorios de la deíxis son la señalización y la actualización (Carbonero Cano, 1979), pudiendo hacer la indicación hacia el espacio, el tiempo, o la persona, elementos estos articuladores de la enunciación.

Los deícticos también han sido vistos, desde una postura semiótica, como símbolos indicadores -como referencia a la tripartición metodológica del signo semiótico puede servirnos Ch. S. Peirce (1940) y P. A. Brandt (1984)- El uso correcto de los términos deícticos reposa en la función indicativa y, especialmente, en ir descubriendo las distinciones simbólicas que son trazadas por los términos deícticos.

Tales símbolos indicadores son acogidos por Jakobson (1975) con la denominación de "conmutadores" — retomando el término de Jespersen-; la significación general de un conmutador no puede definirse sin hacer referencia o remitir al mensaje $\longrightarrow$ al acto de hablaPara Jakobson, igualmente, la naturaleza semiótica de estas unidades descansa en la combinación de ambas funciones.

En la interpretación deíctica la relación espacial designada está ligada a la orientación visual de un observador, que sirve como punto de referencia para la localización de los objetos. En la interpretación inherente esta orientación no juega ningún papel, lo que sirve como punto de referencia es sólo la cara del objeto localizante, sin embargo podemos encontrarnos con formas de ambigüedad en las dos formas de interpretación. Se puede decir que la perspectiva inherente está 
ligada a la función de los objetos, mientras que la perspectiva deíctica a su percepción.

Miller \& Johnson Laird (1976) afirman que, generalmente, las interpretaciones inherentes dominan sobre las deícticas. Si una interpretación deíctica es entendida cuando una interpretación inherente es posible, el emisor comúnmente añadirá "desde mi punto de vista". Esta hipótesis implica que son las propiedades de los objetos puestos en relaciones especiales quienes determinan la elección de la perspectiva. Esto significa que el reconocimiento de la perspectiva elegida no expone casi nunca problemas al receptor. Los participantes de una conversación comparten siempre algunos elementos de un saber común del mundo; esto es porque el emisor puede considerar que el receptor sabe si un objeto $B$ tiene una cara inherente y cuál es la perspectiva apropiada para localizar un objeto $A$ en relación a B. Otro problema diferente será el relativo a los cambios de perspectiva en la comunicación.

En Tanz (1980) encontramos unos criterios adoptados de Fillmore (1971a) que pueden servirnos para una posible caracterización de la perspectiva inherente: para un animal el frente es la parte o cara que tiene el mayor número de órganos de percepción, que llega primero cuando se pone en marcha según su movimiento característico. En los objetos no vivientes, la cosa es más complicada, aunque en general utilizan el modelo de los anteriores: si el objeto tiene una orientación característica en movimiento entonces la parte que llega primero es el delante (Parisi-Castelfranchi, 1969); este criterio vendría prácticamente a coincidir con el llamado por Lyons (1980) "encaramiento". Sin embargo la aplicabilidad de estos criterios es muy relativa, la mínima condición para un locativo intrínseco es una clara diferenciación de sus caras; así, hay objetos para los que sólo podemos encontrar un «delante" según la posición de un hablante o de otro observador.

La interacción de los dos esquemas es de tal forma que el sistema más simple —basado en rasgos intrínsecos- puede ser usado para estabilizar el esquema del sistema más complejo, y, recíprocamente, la confusión con la consideración del sistema más complejo hace retrasar la cristalización final del más simple. En esta consideración, por ejemplo, ninguno de los dos esquemas de términos espaciales puede emerger en el léxico del niño si uno queda atrás. Pero si esto es asi se trata porque los deicticos y los intrínsecos están lexicalizados en una sola forma (al menos en los idiomas comúnmente conocidos). Sin embargo, si tuviésemos un sistema que diferenciara ambos sistemas léxicamente, veriamos que el sistema basado en rasgos intrínsecos es aprendido antes, o que el deíctico es aprendido más tarde (esta es la opinión de 
Tanz (1980), que concuerda con la de Miller \& Johnson-Laird (1976). Podemos concluir este aspecto con las palabras de G.E.T. Holloway (1982: 61) de que "sólo cuando el niño es capaz de coordinar una cantidad de puntos se vista puede dominar las relaciones implicadas en la perspectiva elemental»».

De todo lo expuesto con anterioridad puede haber quedado claramente demostrada la importancia extrema del contexto para la comprehensión de los términos deícticos, aspecto este que en la investigación lingüística nunca ha parecido ponerse en duda. Pero mucho más complicado y conflictivo es la extensión de esta necesidad contextual o de situación de enunciación a los llamados términos intrínsecos, postura esta que propugnamos en nuestra concepción teórica del planteamiento enunciativo y semiótico, al defender que los locativos espaciales - sea en su consideración deíctica o inherente- forman parte del mecanismo articulador de la enunciación por su pertenencia al grupo de las llamadas expresiones ejemplar-reflexivas.

No es nuestra intención, en este trabajo, hacer una exposición y análisis - semántico-pragmático- de los locativos espaciales, sino ver su articulación funcional en el mecanismo semiótico de la enunciación, por ello la caracterización morfofuncional que haremos de tales elementos será realizada metodológicamente con vistas al fin a conseguir.

Categorialmente podemos clasificarlos en 'preposiciones' y 'adverbios'. Las preposiciones piden al menos dos complementos nominales, los adverbios ninguno. Esta diferencia no resulta tanto del contenido de las expresiones en cuestión como de su función pragmática (UllmerEhrich, 1981). Así, proposiciones y adverbios espaciales sirven para localizar un objeto en relación a otro objeto. Pero hay diferencias en lo concerniente al punto de referencia y objeto localizante.

Se emplean proposiciones indicadoras allí donde el punto de referencia no corresponde al objeto localizante. Por contra se hace uso de adverbios en el caso en el que el punto de referencia y el objeto localizante son idénticos.

Funcionalmente la distinción podría ser hecha entre 'nexivos' y 'senalativos'. Estos, son los que no admiten un desarrollo sintagmático que precise el punto de referencia, ya que éste está implícito. Los nexivos serían los que admiten la posibilidad de complementaciones sintagmáticas $u$ oracionales, que informarian sobre el punto de referencia. Es necesario señalar que el texto a veces, por su claridad, no necesita de tal tipo de ampliación explícita, siendo el contexto quien nos muestre el punto de referencia: yo, tú, o algún objeto.

El problema que se nos plantea con esta división es el del estatuto categorial de los nexivos (Carbonero Cano, 1979; López, 1970; Luque, 
1974; Trujillo, 1971, Pottier, 1969), ya que al identificar nexivos con preposiciones y señalativos con adverbios podemos ver alterada la clasificación tradicional de tales elementos; pero si la "situación de enunciación», por su importancia, necesita ser estudiada y elevada a un rango de funcionalidad, hay que admitir que en expresiones tales como "está lejos", al igual que el sujeto que no es ø sino que está dado co(n)textualmente, puesto que la comunicación humana no se realiza mediante frases sino mediante textos, «lejos" es un elemento relacionante donde el objeto localizante está dado co(n)textualmente y sólo desde una lingüistica cuyo objeto de estudio sea el texto -instrumento de comunicación- se podrá dar explicación de fenómenos tales como los anteriores.

Si distinguimos señalativos de nexivos según tengan referencia explícita o implícita, podemos hacer una subdivisión dentro de los señalativos según tengan referencia implícita interna -aquí- yo, Heger, 1974; Vera, 1979 - o referencia implicita externa, conocida en virtud del contexto o cotexto, pero, no contenida en el mismo adverbio, ej.: arriba. Igualmente dentro de los nexivos podemos hacer una subdivisión según la referencia esté explícita sintáctica o co(n)textualmente. Podría verse una confluencia entre los dos últimos subtipos, sin embargo creo que se puede diferenciar ya que las unidades señalativas llevan la referencia implícita siempre en ellos mismos, mientras que los nexivos pueden alternarla sintagmática y $\mathrm{co}(n)$ textualmente. Tras lo dicho parece conveniente introducir un nuevo rasgo diferenciador que sirva para separar la referencia contextual o cotextual: 'endofóricos' vs. 'exofóricos', según su referencia sea, respectivamente, en el cotexto o en el contexto.

Como ya vimos, los locativos deícticos espaciales - sea en su consideración nexiva o señalativa - remiten necesariamente a la "situación de enunciación", formando parte, indiscutiblemente, de las llamadas expresiones ejemplar-reflexivas. El problema que se puede plantear es el de los locativos espaciales intrínsecos o inherentes como integrantes de estas expresiones ejemplar-reflexivas, postura que defendemos. En los casos de los señalativos o de los nexivos con referencia explícita co(n)textual, su inclusión como expresiones ejemplar-reflexivas parece no ofrecer problemas, pues es únicamente en el acto de habla, es decir, en la situación, donde su contenido implícito - y sentido comunicativo en definitiva- puede ser aprehendido en su totalidad. La dificultad estriba en la referencia enunciativa de los nexivos con referencia explícita sintagmática y que —categorialmente-- se verian incluidos en las tradicionales preposiciones. Ya indicamos anteriormente que los locativos espaciales no deícticos no poseen ninguna informa- 
ción sobre el objeto, y es el receptor quien debe recabar de la particular situación toda la información necesaria para identificar el objeto (Parisi-Castelfranchi, 1969). En el caso particular de la preposición hay que considerar que aunque alguna de ellas haya perdidoen determinados usos todo significado no autoriza a negar contenido semántico a las preposiciones en general (García Yebra, 1982). Prueba de que las preposiciones poseen, separadamente, valores semánticos determinados puede ser su incapacidad para conmutar libremente en un contexto dado (Trujillo, 1971). Su valor puede ser más o menos impreciso, más o menos difícil de determinar a partir de la inmensa cantidad de realizaciones, pero es un hecho incontrovertible que no hay dos preposiciones que coincidan absolutamente. Las coincidencias parciales en ciertos contextos - neutralizaciones'- se dan también en otros elementos de la lengua y no son una prueba de denegación. Es preciso igualmente considerar ciertos casos en que la preposición se suelda al elemento regente o regido, en ambas ocasiones la preposición carece de carga semántica; pero se trata de esquemas de norma fijado históricamente en los que es imposible un análisis sincrónico de las preposiciones como tales: sólo cabe el análisis como totalidad, pero esto no corresponde ya al nivel de las preposiciones, sino al de las lexías así formadas, en tanto que elementos de valor funcional único. Conviene por tanto distinguir metodológicamente (Trujillo, 1971) los usos en que la preposición es «elegida» e indica el valor de la relación, de estos otros en que a lo sumo es un mero índice hipotáctico, pues aunque históricamente (Alvar-Pottier, 1983) siempre pueda justificarse un uso preposicional, sincrónicamente no ocurre así.

Teniendo en cuenta que la preposición es un elemento de relación, su significación no es tan concreta como en otras palabras, es fundamentalmente informativa (López, 1970); de ahí que se necesite del contexto para concretarse en cada caso y que tome su significación en el discurso mediante la función. Avanzando en estas propuestas Luque (1974) llegará a decir que la preposición sólo significa en el contexto. Siguiendo con el valor del contexto en el estudio de las preposiciones parece obvio señalar que el valor semántico de los términos relacionados establece límites a las posibilidades de conmutación. La elección paradigmática no suele ser enteramente libre. La carga semántica de cada preposición resulta a veces incompatible con determinados contornos semánticos (López, 1970; Trujillo, 1971). Creo pues que queda apuntalado el valor semántico de las preposiciones, así como la necesidad de recurrir a un estudio contextual para determinar su uso y significado. Forman parte, por tanto, de las expresiones ejemplar-reflexivas. 
Desde una perspectiva psicolingüística los estudios de Weissenborn (1981) y Tanz (1980) vienen a argüir con nuevas razones la necesidad de los locativos espaciales de acoger en su estudio, significado y uso, el contexto pragmático o la situación de enunciación, tanto desde el punto de vista de la adquisición como desde la comprehensión.

\section{Locativos y coherencia textual}

Difícilmente podría uno orientarse en un texto si el lenguaje no hubiese afrontado ya en cada texto determinadas instrucciones o señales, que pueden concebirse como indicadores en el terreno de desarrollo del texto (Weinrich, 1982). Greimas (1983:272) también hace referencia a este fenómeno:

«Mientras que la semiótica narrativa, gracias a la canonicidad de sus estructuras consigue establecer niveles homogéneos y recurrentes de la lectura del texto, la permanencia discursiva, por su lado, parece descansar en gran parte sobre los procedimientos de anaforización, tanto gramaticales como semánticos, que se presentan como aplicaciones del principio general de expansión y condensación semánticas, rigiendo toda productividad lingüística: pulsaciones que ritman el texto en su superficie, y que funcionan como relevos de la memoria textual y garantizan en todo momento, la conservación de las adquisiciones semánticas del discurso".

Una de estas señales podrian ser los locativos espaciales, y en especial los deícticos (recordemos a este respecto la funcionalidad tanto exofórica como endofórica de los locativos).

Para una exacta comprensión de estos mecanismos de coherencia textual (Dressler, 1974; Bernárdez, 1982), que es como pueden ser considerados los locativos espaciales, hemos de fijarnos en su composición dentro del apartado de los mecanismos de identificación textual (Ramón Trives, 1983), y que configura un nuevo tipo de isosemia en la estructura organizativa del fenómeno discursivo. El cuadro o modelo operativo de este tipo de isosemia que compone la identificación es el que exponemos a continuación (Ramón Trives, 1983:258) y donde pese a parecer limitarse el funcionamiento de los locativos a los locativos deícticos, creo oportuno una futura incorporación de los locativos intrínsecos en funcionamiento parejo al de los deícticos, lo cual supon- 
dría nuevas especificaciones en el cuadro operativo articulador de las identificaciones.

Por otra parte, el funcionamiento de los deicticos parece circunscribirse a un solo apartado —el de anaforización morfológica-, sin embargo podriamos preguntarnos hasta qué punto su papel de actualizador le hace entrar en interacción con casi todos los componentes. Así, por ejemplo, en el componente de condensación clasemática por intercambio léxico-semántico, «hombre» identifica a «Juan», el interrogante -en mi opinión- estriba en saber si la aportación referencial como actualizador del deíctico acompañante puede ayudar a la identificación de forma necesaria, siendo por tanto preciso una interacción mutua. Hipótesis quizá demasiado arriesgada, pero de lo que no cabe duda es de la gran frecuencia con que suelen verse acompañados en el discurso los distintos mecanismos de identificación y determinados actualizadores deícticos.

En la distinción efectuada entre Dictum y Modus, el primero se refiere a lo que Coquet llama discurso sin yo (Darrault, 1976), sin la ingerencia del diálogo. Al aludir al modus se refiere al discurso de la persona que habla, condicionada a la voluntad del que habla. Se trata también de un elemento de identificación ya que el hablante tiene que manifestar el modo de utilización de la lengua (Ramón Trives, 1980) por distintos mecanismos de modalidades.

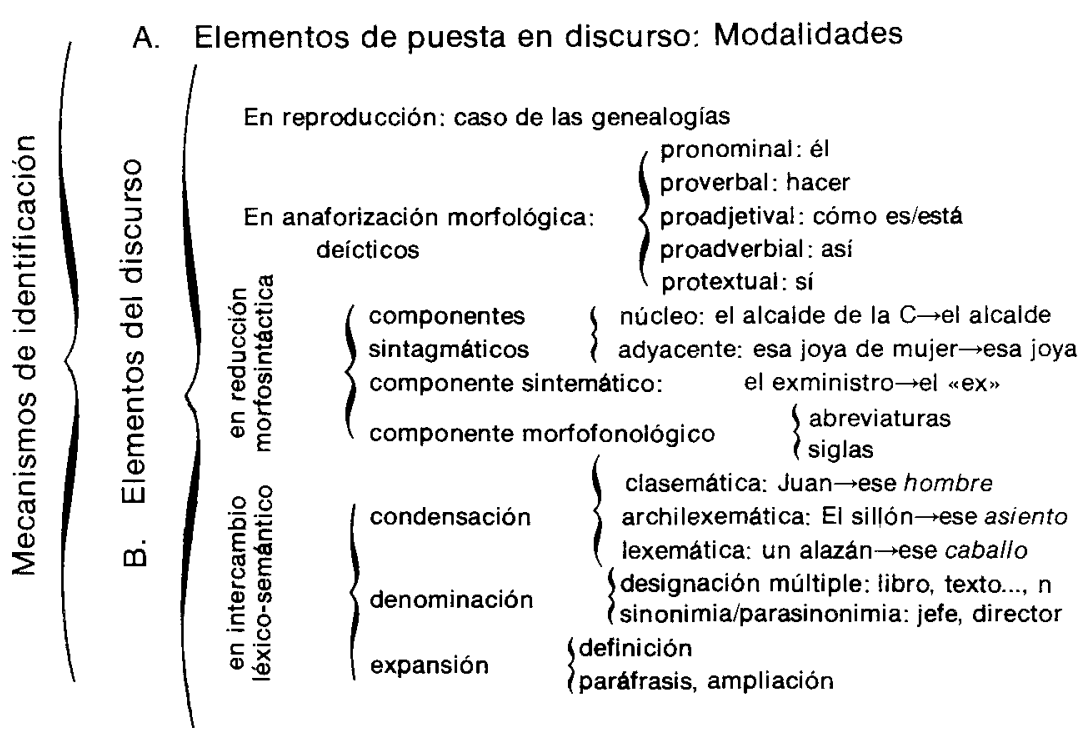


No hemos de olvidar que el texto reclama la pluralidad como razón de su existencia. Los mecanismos de identificación y, en especial, los operadores décticos fijan en su unicidad significativa pragmática -movidos por la intencionalidad del hablante, que configura el textoel sentido unitario del texto desde la plurivalencia significativa de la lengua:

"Los mecanismos de identificación son como los diques de contención que aseguran que la multiplicidad de probabilidades que emanan de la condición abierta de las estructuras lingüisticas, cristalicen en texto con una estructura terminal dada, cerrada o abierta, pero intencionalmente dada, a la postre, como piedra de toque incuestionable de una multiplicidad de interpretaciones, en la medida en que el texto utiliza a la lengua (potencial interpretativo cerrado del texto) o, por el contrario, el texto es lengua, en su más íntima razón de ser (potencial interpretativo abierto del texto creativo o artístico-literario)». Ramón Trives, 1983:252-253.

En la medida en que el hablante desee dotar a su expresión de condición artística, cederá a la concretud identificadora, dejando su texto pragmáticamente abierto para los amplios horizontes de lo simbólico y plurivalente, esencial en la creación artística. (Ramón Trives, 1977).

El conjunto de unidades identificativas tiene como objeto general conectar la denominación con el denotado concreto, y, por tanto, estas unidades sirven de cauce del mecanismo de seguridad del sentido textual, es pues un correlato de la plurivalencia denominativa del sistema, una exigencia del proyecto comunicativo puesto que éste pretende comunicar un mensaje, un sentido desde las servidumbres que impone la plurivalencia denominativa del sistema. Estas unidades identificativas se encargan de dar cauce comprensivo a esas unidades incomprensibles.

El capitulo de la identificación forma parte del mecanismo de la 'isotopía', la cual es necesaria para que exista cualquier texto en cualquier dimensión, pero la isotopía es susceptible de distintos grados de coincidencia, de distinta redundancia, reproducción de elementos; puede ir de lo marginal o clasemático pasando por lo archilexemático, lo implicativo, para llegar a lo identificativo propiamente dicho.

Evidentemente estos cuatro estadios son mecanismos de identificación pero se ve que en el caso del mecanismo clasemático lo que interesa es la clase, en otras ocasiones es el archilexema, también el lexema o semema (implicación), en la medida en que estos elementos 
los prevé el sistema y son elementos estructurales donde algún elemento de los que se encuentran en una misma isotopia tiene la coincidencia en una clase, etc. Pero en estos casos se trata de isotopía estructural, en cuanto que la relación entre esas unidades de la isotopía es de composición; la sistemática estructural de una lengua prevé esas isotopías. Pero estos factores de isotopía no son los únicos de los que se vale el hablante, tenemos elementos que forman la isotopía no estructural que son los mecanismos identificativos propiamente dichos: no se trata de buscar el parentesco clasemático, archilexemático o semémico, sino de identificar una unidad en toda su complejidad discursiva:

«La isosemia por identificación, por su carácter operativo, puede hacer referencia tanto a unidades subfrásticas, frásticas, interfrásticas, como a microtextos o unidades narrativas. Pueden identificarse actantes-circunstantes de todo tipo, tanto por procedimientos explícitos, específicos o explícitos genéricos, como por procedimientos no explicitos o presupuestos». (Ramón Trives, 1979:219).

Así pues, y para una correcta comprensión de los mecanismos de identificación, incorporamos a continuación el cuadro esquematizador de la isotopia con la inclusión de la isotopía identificativa dentro del marco de intersecciones operativas que se pueden adoptar. (Ramón Trives, 1979: 218; 1983: 256).

Tipos de
isotopía
semio-
textual $\left\{\left\{\begin{array}{l}\text { afinidad } \\ \text { selección } \\ \text { implicación } \\ \text { identificación }\end{array}\right\}\left\{\begin{array}{l}\text { actancial } \\ \text { predicacional } \\ \text { predicactancial }\end{array}\right\}\left\{\begin{array}{l}\text { explícito } \\ \text { pre/supuesto }\end{array}\left\{\begin{array}{l}\text { extralin- } \\ \text { gǘstico } \\ \text { discursivo } \\ \text { lingǘístico }\end{array}\right\}\right\}\left\{\begin{array}{l}\text { nuclear } \\ \text { internuclear }\end{array}\right\}\left\{\begin{array}{l}\text { específico } \\ \text { genérico }\end{array}\right\}\right.$

No podemos dejar de mencionar junto a este apartado dedicado a la coherencia textual, dada por isosemia, la importancia capital que para tal fin puede llegar a tener el dispositivo gráfico-composicional en cuanto elemento imprescindible de las convenciones anafóricas:

«La composición o disposición gráfico-espacial es la conformación congénita de las realidades lingüisticas mencionadas - textos de lengua objeto, operativos en el proceso comunicativo por medio de su materialidad gráfica-, ya como punto final del proceso de génesis o producción lingüística, ya como punto inicial del proceso de síntesis o interpretación lingüística —así, al me- 
nos, se manifiesta en la generalidad de los casos-. Está además, estrechamente ligada a problemas básicos, como es el de la naturaleza lineal de los signos lingüísticos y la serie de relaciones, especialmente sintagmáticas, que le son propias" (Jiménez Cano, 1983: 230).

Podría llegar a pensarse por tanto (Jiménez Cano, 1983) que el dispositivo gráfico composicional es consecuencia última y resultante del lenguaje humano. $Y$ en este punto es necesario especificar que no nos referimos siempre a textos escritos, también pueden ser orales pero sometidos a un esquema retórico-escritural de base.

La caracterización del componente gráfico-composicional espacial está estrechamente vinculada con las distinciones entre géneros históricos, ya que cada género implanta unas determinadas características gráfico-composicionales. Este última idea sustenta la base de la existencia de espacios y distribuciones gráficas convencionalizadas que formarian parte de la estructura cognoscitivo-textual de un hablante cualificado, e incidirian en la disposición y organización de los contenidos textuales generados. Ejemplos de tales espacios puede ser el prólogo, capítulos, epílogos, etc. Al hacer depender (Jiménez Cano, 1983) esta serie de elementos de la estructura cognoscitivo-textual de un hablante cualificado, se hace necesario suponer el conocimiento de las convencionalizaciones cognoscitivas de que dispone en lo relativo a la espacialidad.

El componente gráfico composicional no restringe su funcionalidad a la traducción de lo fónico, sino que también debe dar cuenta de los

COMPONENTE GRAFICO-COMPOSICIONAL

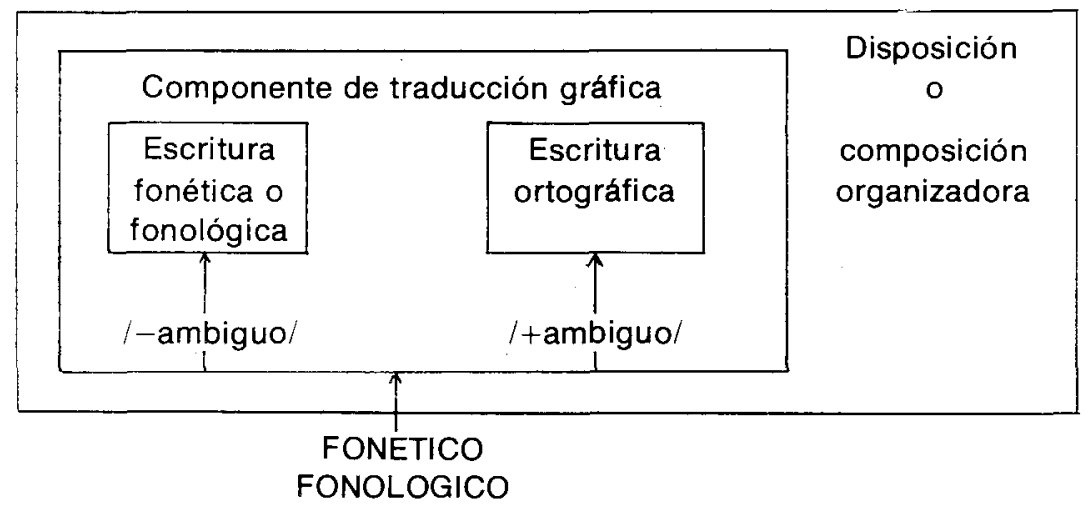


elementos compositivos y organizadores que garantizan la construcción y manifestación externa de los textos escritos. El siguiente esquema es muy clarificador de estos aspectos: Jiménez Cano, 1983: 239.

La disposición o composición organizadora coincide con lo que Greimas, apoyado en criterios pragmáticos espacio-temporales denomina «dispositivo gráfico» (Greimas, 1983).

Ajustarse a un grado de convencionalidad mayor o menor en la disposición de los textos escritos puede interpretarse como el deseo por parte del autor del texto de implicar al lector en mayor o menor medida. Es asi como podrán explicarse efectos narrativos conducentes a la creación del suspense, etc., pero el más claro ejemplo del uso metalingüístico del espacio textual es el de la serie de referencias convencionalizadas de carácter anafórico o catafórico en la dinámica intratextual o cotextual. A esto podrían añadirse (Dressler, 1974) ciertas convencionalizaciones gráficas —cursiva, ortografía, etc.-, pero lo que sí nos parece muy importante en la disposición espacial del texto es que ya que los textos escritos suelen ser más ambiguos que los orales, se recurra a la disposición de las palabras como fenómeno de focalización (Contreras, 1983), con lo cual entrariamos dentro del gran problema de la dialéctica tema-rema.

\section{Conclusiones}

Parece pues probada la importancia del espacio lingüístico en su funcionamiento como uno de los articuladores del enunciado y enunciación en la dinámica de puesta en discurso de la lengua española. Es obvio que este estudio no es abarcador ni concluyente, tampoco lo pretende ser, pero sí quiere abrir el paso al estudio de este fenómeno -junto con la temporalización y actorialización-como componentes de esa sintaxis discursiva greimasiana constituyente del recorrido generativo.

\section{Referencias bibliográficas}

Albaladejo Mayordomo, T.; García Berrio, A. (1983), «La Lingüística del Texto", en F. Abad y A. García Berrio (Coords.), Introducción a la Lingüistica, Alhambra, Madrid.

Alvar, M-Pottier, B. (1983), Morfologia Histórica del Español, Madrid, Gredos. 
Antinucci, F. (1974), «Sulla deissi», Lingua e Stile, IX, pp. 223-247.

- (1976), «Ancora sulla deissi», Lingua e Stile, I, pp. 127-131.

Austin, J. L. (1971), Palabras y acciones, Buenos Aires, Paidós.

Bar-Hillel, Y. (1973), «Expresiones indicadoras», en Th. M. Simpson (ed.):

Semántica filosófica: problemas y discusiones, Buenos Aires, Siglo XXI, pp. 95-118.

Benveniste, E. (1971), Problemas de Lingüistica general, I, México, Siglo $X X I$.

Bernárdez, E. (1982), Introducción a la Lingüística del Texto, Madrid, Espasa-Calpe.

Boudon, P. (1981), La Sémiotique des lieux, Klincksieck, Paris.

Brandt, P. A. (1984), “El Sujeto que habla», Poetyca et Analytica, 1, pp. $131-154$.

Bühler, K. (1979), Teoría del lenguaje, Alianza, Madrid.

Carbonero Cano, P. (1979): Deíxis espacial y temporal en el sistema lingüístico, Universidad de Sevilla.

Cinque, G. (1976), «Sulla deissi linguistica», Lingua e Stile, I, pp. 101-126. Contreras, H. (1983), El orden de palabras en español, Cátedra, Madrid.

Darrault, I. (ed.) (1976), «Modalités, logique, linguistique et sémiotique», Langages, 43.

van Dijk, T. A. (1980), Texto y contexto, Madrid, Cátedra.

Dressler, W. (1974), Introduzione alla linguistica del testo, Roma, Officina. Ducrot, O. (1981), Decir y no decir, Barcelona, Anagrama.

Ducrot, O.; Todorov, T. (1974), Diccionario enciclopédico de las ciencias del lenguaje, Buenos Aires, Siglo XXi.

Fillmore, Ch. J. (1966), "Deictic categories in the semantic of "come", Foundations of Language, 2, pp. 219-227.

- (1971a), "Space», Unpublished Ms. Summer Program in Linguistics, University of California at Santa Cruz.

- (1971b), sHow to know whether you'r coming or going", en $\mathrm{K}$. Hydgaard-Jensen (ed.), Linguistik, Athenäaum, pp. 369-379.

- (1972), "Subjects, speakers and roles», en Davidson \& Hartman (eds.), Semantics of Natufal Logics, D. Reiden Publishing company, Dordrecht-Holland, pp. 1-24.

García Yebra, A. (1982), Teoria y práctica de la traducción, Madrid, Gredos.

Greimas, A. J. (1971), Semántica Estructural, Madrid, Gredos.

- (1973), En torno al sentido, Fragua, Madrid.

- (1980a), «Description et narrativité», Documents de Recherche, 13; E.H.E.S.S.-C.N.R.S., pp. 4-27.

- (1980b), Semiótica y ciencias sociales, Fragua, Madrid.

- (1983), La Semiótica del Texto, Paidós, Barcelona. 
Greimas, A. J.; Courtés, J. (1982), Semiótica. Diccionario razonado de la teoria del lenguaje, Madrid, Gredos.

Heger, K. (1974), «Deíxis personal y persona gramatical», Teoria Semántica II, Madrid, Alcalá.

Holloway, G. E. T. (1982), La concepción del espacio en el niño según Piaget, Paidós, Barcelona.

Huddleston, R. (1969), «Some observations of tense and deixis in English", Language, 45, pp. 777-806.

Jakobson, R. (1975), "Los conmutadores, las categorías verbales y el verbo ruso", Ensayos de Lingüistica General, Barcelona, Seix Barral, pp. 307-332.

Jiménez Cano, J. M. (1983), «Presupuestos teóricos para una grafémica textual», Estudios de Lingüística, 1, Universidad de Alicante, pp. 227-247.

López, M. ${ }^{2}$ L. (1970), Problemas y métodos en el análisis de las preposiciones, Madrid, Gredos.

Luque Durán, J. (1974), Las Preposiçiones, SGEL, Madrid.

Lyons, J. (1980), Semántica, Teide, Barcelona.

Marcos Marín, F. (1980), Curso de Gramática Española, Cincel, Madrid.

Miller, G. A.; Johnson Laird, P. N. (1976), Language and Perception, Harvard University Press, Cambridge, Massachussets.

Muntañola-Thornberg, J. (1977), «Rémarques épistémologiques sur la sémiotique des lieux», Communications, 27, pp. 13-27.

Parisi, G.; Castelfranchi, C. (1969), «Analisi semantica dei locativi spaciali», La Sintassi, Roma, Bulzoni.

Peirce, Ch. S. (1940), The philosophy of Peirce: Selected writings, edición de J. Buchler, London.

Pottier, B. (1969), Systématique des élèments de relation, Paris, Klincksieck.

Petöfi, J. S.; Garcia Berrio, A. (1979), Lingüística del Texto y Crítica Literaria, Comunicación, Madrid.

Ramón Trives, E. (1977), «Lengua y poesía», en Homenaje al Prof. Muñoz Cortés II, Universidad de Murcia, pp. 589-604.

- (1979), Aspectos de Semántica lingüístico-textual, Madrid, Alcalá.

- (1980), «Nuestro hablar, proceso pragmáticamente no exento», Monteagudo, 68, pp. 13-20.

- (1983), «Mecanismos de identificación y nexuación compleja en la dinámica textual», Estudios de Lingüistica, 1, Universidad de Alicante, pp. 249-261.

Récanati, F. (1981), La transparencia y la enunciación. Introducción a la Pragmática, Hachette, Buenos Aires. 
Ryle, G. (1957), "The theory of Meaning", en G. Ryle, Collected Papers, vol. II, Londres, 1971.

Schmidt, S. J. (1977), Teoria del Texto, Madrid, Cátedra.

Searle, J. R. (1980), Actos de habla, Madrid, Cátedra.

Strawson, P. F. (1970), "Phrase et acte de parole», Langages, 17, pp. 19-33.

Tanz, Ch. (1980), Studies in the acquisition of deictic terms, Cambridge, University Press.

Trujilio, R. (1971), «Notas para un estudio de las preposiciones españolas", BICC, XXVI, pp. 234-279.

Ullmer-Ehrich, V. (1981), L'usage des prépositions indexicales dans un discours descriptif. La perspective déictique et la perspective inhérente", Analyse des prépositions, Max Niemeyer Verlag, Tübingen, pp. 224-250.

Vera, A. (1979), «La estructura del campo deíctico-personal en español: el Pronombre», Analecta Malacitana, II, 1, pp. 3-25.

Weinrich, H. (1979), "Los tiempos y las personas», Dispositio, ESTUDIOS, vol. III, n. ${ }^{\circ} 7-8$, Departament of Romance Language, University of Michigan, pp. 21-38.

- (1982), Lenguaje en Textos, Madrid, Gredos.

Weissenborn, J. (1981), «L'acquisition des prépositions spatiales: problémes cognitifs et linguistiques", Analyse des Prépositions, Max Niemeyer Verlag, Tübingen, pp. 251-285.

Wittgenstein, L. (1973), Tractatus logico-philosophicus, Alianza, Madrid. Wunderlich, D. (1972), «Pragmatique, situation d'énonciation et deixis», Langages, 26, pp. 34-58. 